\section{References}

1. Uchida N, Isihara H, Shibamura H, Kyo Y, Ozawa M. Midterm results of extensive primary repair of the thoracic aorta by means of total arch replacement for an acute type A aortic dissection. J Thorac Cardiovasc Surg. 2006;131:862-7.

2. Kato M, Kuratani T, Kaneko M, Kyo S, Ohnishi K. The results of total arch graft implantation with open-stent graft placement for type A aortic dissection. J Thorac Cardiovasc Surg. 2002;123:1035-40.
3. Kubota H, Endo H, Sudo K. New open-stent-graft delivery system: the CLATE flexible metal graft holder. Interactive Cardiovasc Thorac Surg. 2006;5:333-5.

4. Dobrilovic N, Elefteriades JA. Stenting the descending aorta during repair of type A dissection: technology looking for an application? J Thorac Cardiovasc Surg. 2006;131:777-8.

\title{
A meta-analysis of comparative studies of endovascular versus open repair for blunt thoracic aortic injury
}

\author{
Hisato Takagi, MD, PhD, Norikazu Kawai, MD, and Takuya Umemoto, MD, PhD, Shizuoka, Japan
}

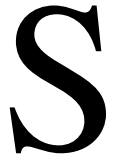

everal recent comparative studies $^{1-5}$ of endovascular (EVR) versus open repair (OR) for blunt thoracic aortic injury (BTAI) suggest that EVR may be associated with a reduction in mortality. Such comparisons are, however, hampered by the small number of cases, owing to the relative rarity of this condition. ${ }^{4}$ Therefore, the appropriate role of EVR for BTAI remains unclear. We performed a meta-analysis of all comparative studies of EVR versus OR for BTAI to date.

\section{Materials and Methods}

All comparative studies of EVR versus OR for BTAI were identified by a 2-level search strategy. First, a public domain database (MEDLINE) was searched using a Web-based search engine (PubMed). Second, relevant studies were identified through a manual search of secondary sources including references of initially identified articles and a search of reviews and commentaries. The MEDLINE database was searched from January 1966 to December 2007. MeSH keywords included "Aortic Rupture," "Aorta," "Wounds and Injuries," "Aortic Aneurysm, Thoracic," "Stents," and "Comparative Study." Studies considered for inclusion met the following criteria: the design was a comparative study of EVR versus OR; the study population was patients with BTAI; and main outcomes included mortality. Data regarding detailed inclusion criteria and mortality were abstracted (as available) from each individual study. For each study, data regarding mortality in both the EVR and OR groups

From the Department of Cardiovascular Surgery, Shizuoka Medical Center, Shizuoka, Japan.

Received for publication Dec 19, 2007; accepted for publication Jan 13, 2008.

Address for reprints: Hisato Takagi, MD, PhD, Department of Cardiovascular Surgery, Shizuoka Medical Center, 762-1 Nagasawa, Shimizu-cho, Suntogun, Shizuoka 411-8611, Japan (E-mail: kfgth973@ybb.ne.jp).

J Thorac Cardiovasc Surg 2008;135:1392-4

$0022-5223 / \$ 34.00$

Copyright $\odot 2008$ by The American Association for Thoracic Surgery doi:10.1016/j.jtcvs.2008.01.033 were used to generate odds ratios and $95 \%$ confidence intervals (CIs). Study-specific estimates were combined using inverse variance-weighted averages of logarithmic odds ratios in a random-effects model. Between-study heterogeneity was analyzed by standard $\chi^{2}$ tests. Sensitivity analyses were performed to assess the contribution of each study to the pooled estimate by excluding individual studies one at a time and recalculating the pooled odds ratio estimates for the remaining studies. Publication bias was assessed graphically by a funnel plot and mathematically by an adjusted rank-correlation test.

\section{Results}

Our search identified 17 retrospective nonrandomized comparative studies $^{1-5, \text { E1-E12 }}$ of EVR versus OR for BTAI. The baseline patient characteristics are summarized in Table 1. In $11^{1-5, \mathrm{E} 3, \mathrm{E} 4, \mathrm{E} 7, \mathrm{E} 8, \mathrm{E} 11, \mathrm{E} 12}$ of the 17 studies, the EVR and OR groups had similar preoperative variables including the injury severity score. Fifteen of the 17 individual studies demonstrated a statistically nonsignificant benefit of EVR over OR for mortality, whereas only one study ${ }^{\mathrm{E} 10}$ demonstrated a statistically nonsignificant mortality reduction with OR over EVR. Pooled analysis of all the 17 studies (representing 565 patients) demonstrated a statistically significant $57 \%$ reduction in mortality with EVR relative to OR $(8.1 \%$ in the EVR group vs $20.8 \%$ in the OR group; odds ratio, 0.43 ; $95 \%$ CI, $0.25-0.76 ; P<.01$ ) (Figure 1, upper panel). There was neither study heterogeneity of results $(P=.96)$ nor evidence of significant publication bias $(P=.32)$. To assess the impact of qualitative heterogeneity in study design and patient selection on the pooled effect estimate, we performed several sensitivity analyses. In general, exclusion of any single study from the analysis did not substantively alter the overall result of our analysis. Additionally, when data from the 11 studies $^{1-5, E 3, E 4, E 7, E 8, E 11, E 12}$ with similar preoperative variables in both groups were pooled $(\mathrm{N}=393)$, EVR was associated with a $62 \%$ reduction in mortality relative to OR that remained statistically significant $(7.5 \%$ vs $24.1 \%$; odds ratio, $0.38 ; 95 \%$ CI, $0.20-0.73 ; P<.01)$ (Figure 1 , lower panel). There was neither study heterogeneity of results $(P=.91)$ nor evidence of significant publication bias $(P=.24)$. 
TABLE 1. Characteristics of the included studies

\begin{tabular}{|c|c|c|c|c|c|c|c|c|c|c|}
\hline \multicolumn{3}{|c|}{ Study } & \multicolumn{2}{|c|}{ Patients } & \multicolumn{3}{|c|}{ Age (y) } & \multicolumn{3}{|c|}{ Injury severity score } \\
\hline Author & Publication & Period & EVR & OR & EVR & $\mathbf{O R}$ & $P$ & EVR & OR & $\boldsymbol{P}$ \\
\hline Akowuah ${ }^{4}$ & $\begin{array}{l}J \text { Thorac } \\
\text { Cardiovasc Surg. } \\
\text { 2007;134:897-901 }\end{array}$ & 2000-2006 & 7 & 8 & $32 \pm 15$ & $28 \pm 9$ & 0.4 & $42 \pm 5$ & $44 \pm 13$ & 0.3 \\
\hline Amabile $^{\mathrm{E} 1}$ & $\begin{array}{l}\text { J Vasc } \\
\quad \text { Surg. 2004;40:873-9 }\end{array}$ & 1998-2004 & 9 & 11 & $30.9 \pm 9.6$ & $32.4 \pm 9.8$ & 0.74 & NR & NR & NR \\
\hline Andrassy ${ }^{\mathrm{E} 2}$ & $\begin{array}{l}\text { J Trauma. 2006;60: } \\
\text { 765-72 }\end{array}$ & NR & 15 & 16 & $38.7 \pm 17.5$ & $39.1 \pm 17.5$ & 0.94 & NR & NR & NR \\
\hline Broux $^{\mathrm{E} 3}$ & $\begin{array}{l}\text { Intensive Care } \\
\quad \text { Med. 2006;32:770-4 }\end{array}$ & 1995-2005 & 13 & 17 & $46 \pm 18$ & $35 \pm 15$ & NR & $46 \pm 18$ & $35 \pm 12$ & NS \\
\hline Buz $^{1}$ & $\begin{array}{c}\text { Eur J Cardiothorac } \\
\text { Surg. doi:10.1016/ } \\
\text { j.ejcts.2007.10.017 }\end{array}$ & 1987-2007 & 39 & 35 & 36 (mean) & 36 (mean) & NS & 41 (median) & 34 (median) & NS \\
\hline Cook $^{\text {E4 }}$ & $\begin{array}{l}\text { J Thorac } \\
\text { Cardiovasc Surg. } \\
\text { 2006;131:594-600 }\end{array}$ & 2000-2005 & 19 & 24 & NR & NR & NR & $38.9 \pm 10$ & $34.5 \pm 9.9$ & 0.1 \\
\hline Doss $^{\mathrm{E5}}$ & $\begin{array}{l}\text { Ann Thorac } \\
\text { Surg. 2003;76: } \\
1465-70\end{array}$ & 1999-2002 & 4 & 12 & NR & NR & NR & NR & NR & NR \\
\hline Kasirajan $^{\mathrm{E} 6}$ & $\begin{array}{l}\text { Ann Vasc } \\
\quad \text { Surg. 2003;17:589-95 }\end{array}$ & 1999-2002 & 5 & 10 & $38 \pm 19$ & $44 \pm 24$ & NR & $42 \pm 9$ & $32 \pm 11$ & NR \\
\hline Kokotsakis $^{2}$ & $\begin{array}{l}\text { Ann Thorac } \\
\text { Surg. 2007;84: } \\
\text { 1965-70 }\end{array}$ & 2002-2006 & 22 & 10 & $26.20 \pm 2.14$ & $42.45 \pm 4.11$ & 0.01 & $48.8 \pm 5.3$ & $48.13 \pm 4.54$ & 0.92 \\
\hline Lebl $^{E 7}$ & $\begin{array}{l}\text { Arch Surg. } \\
\text { 2006;141:177-80 }\end{array}$ & 1997-2003 & 7 & 10 & $59 \pm 8$ & $39 \pm 5$ & $0.10^{*}$ & $35.1 \pm 3.7$ & $34.9 \pm 3.4$ & $0.48^{*}$ \\
\hline Midgley $^{5}$ & $\begin{array}{l}\text { J Vasc } \\
\quad \text { Surg. 2007;46:662-8 }\end{array}$ & 1994-2006 & 12 & 16 & $43.8 \pm 19.9$ & $42.9 \pm 18.6$ & 0.90 & $37.9 \pm 12.6$ & $45.8 \pm 18.2$ & 0.28 \\
\hline $\mathrm{Ott}{ }^{\mathrm{E} 8}$ & $\begin{array}{l}\text { J Trauma. 2004;56: } \\
\text { 565-70 }\end{array}$ & $1991-2002$ & 6 & 12 & 43.5 (median) & 31.5 (median) & 0.18 & 46 (median) & 47.5 (median) & 0.33 \\
\hline Pacini $^{E 9}$ & $\begin{array}{l}\text { J Thorac } \\
\text { Cardiovasc Surg. } \\
\text { 2005;129:880-4 }\end{array}$ & 1980-2003 & 15 & 51 & NR & NR & NR & NR & NR & NR \\
\hline Reed $^{\mathrm{E} 10}$ & $\begin{array}{l}\text { J Vasc } \\
\quad \text { Surg. 2006;43:684-8 }\end{array}$ & 2000-2005 & 13 & 11 & $54.8 \pm 22.7$ & NR & NR & 40 (mean) & NR & NR \\
\hline Riesenman $^{3}$ & $\begin{array}{l}\text { J Vasc } \\
\quad \text { Surg. 2007;46:934-40 }\end{array}$ & 1993-2006 & 14 & 48 & 40.7 (mean) & 40.2 (mean) & 0.931 & 38 (mean) & 41 (mean) & 0.491 \\
\hline Rousseau $^{\mathrm{E} 11}$ & $\begin{array}{l}\text { J Thorac } \\
\text { Cardiovasc Surg. } \\
\text { 2005;129:1050-5 }\end{array}$ & $1981-2003$ & 29 & 35 & $37 \pm 19$ & NR & NR & $35.0 \pm 2.1$ & $33.0 \pm 1.9$ & NS \\
\hline Stampfl $^{\mathrm{E} 12}$ & $\begin{array}{l}\text { Eur J Vasc } \\
\quad \text { Endovasc Surg. } \\
\text { 2006;31:475-80 }\end{array}$ & 1993-2004 & 5 & 5 & $47.2 \pm 19.3$ & $30.0 \pm 16.0$ & 0.17 & $53.2 \pm 10.8$ & $43.8 \pm 8.9$ & 0.17 \\
\hline Total & & & 234 & 331 & & & & & & \\
\hline
\end{tabular}

EVR, Endovascular repair; $O R$, open repair; $N R$, not reported; $N S$, not significant. *Comparing endovascular repair, open repair, and medical management.

\section{Discussion}

The potential benefits of EVR over OR for BTAI include no thoracotomy, no need for single lung ventilation, decreased use of systemic anticoagulation, avoidance of aortic crossclamping, and less blood loss. ${ }^{5}$ Experience of EVR for BTAI is, however, limited and difficult to study given the low prevalence of patients who survive to presentation. ${ }^{3}$ Although there is a clear trend toward better results for EVR in comparative studies of EVR versus OR, the relatively low power of these studies was not able to demonstrate a statistically significant difference in mortality. The present meta-analysis of all comparative studies of EVR over OR for BTAI to date, including several sensitivity analyses, demonstrated a statistically significant benefit of EVR over OR for mortality. The main limitation of our study is to include merely retrospective nonrandomized comparative studies that allow selection and reporting biases for outcomes in favor of EVR. Nevertheless, the results of the present meta-analysis are not the best but are 


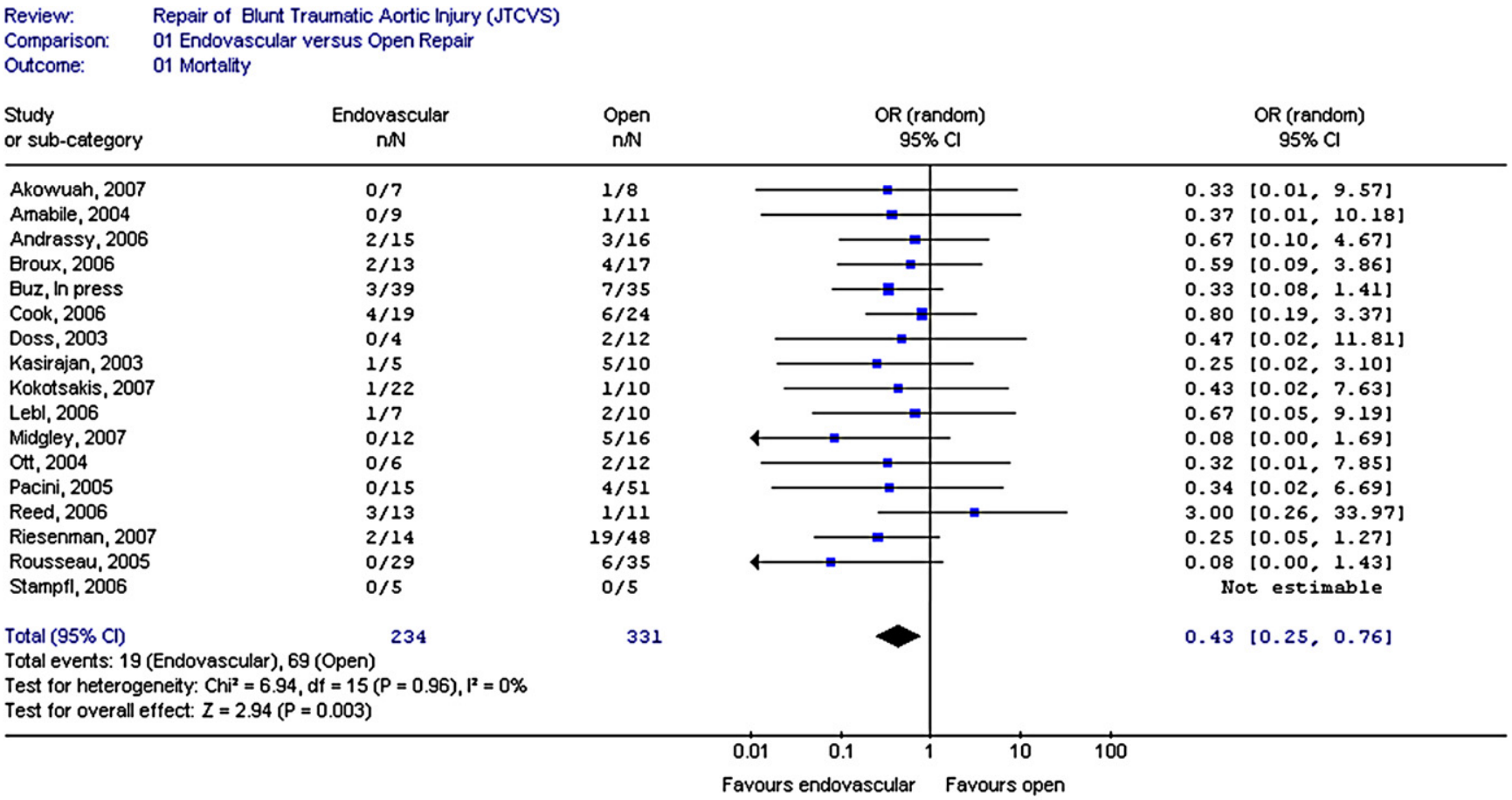

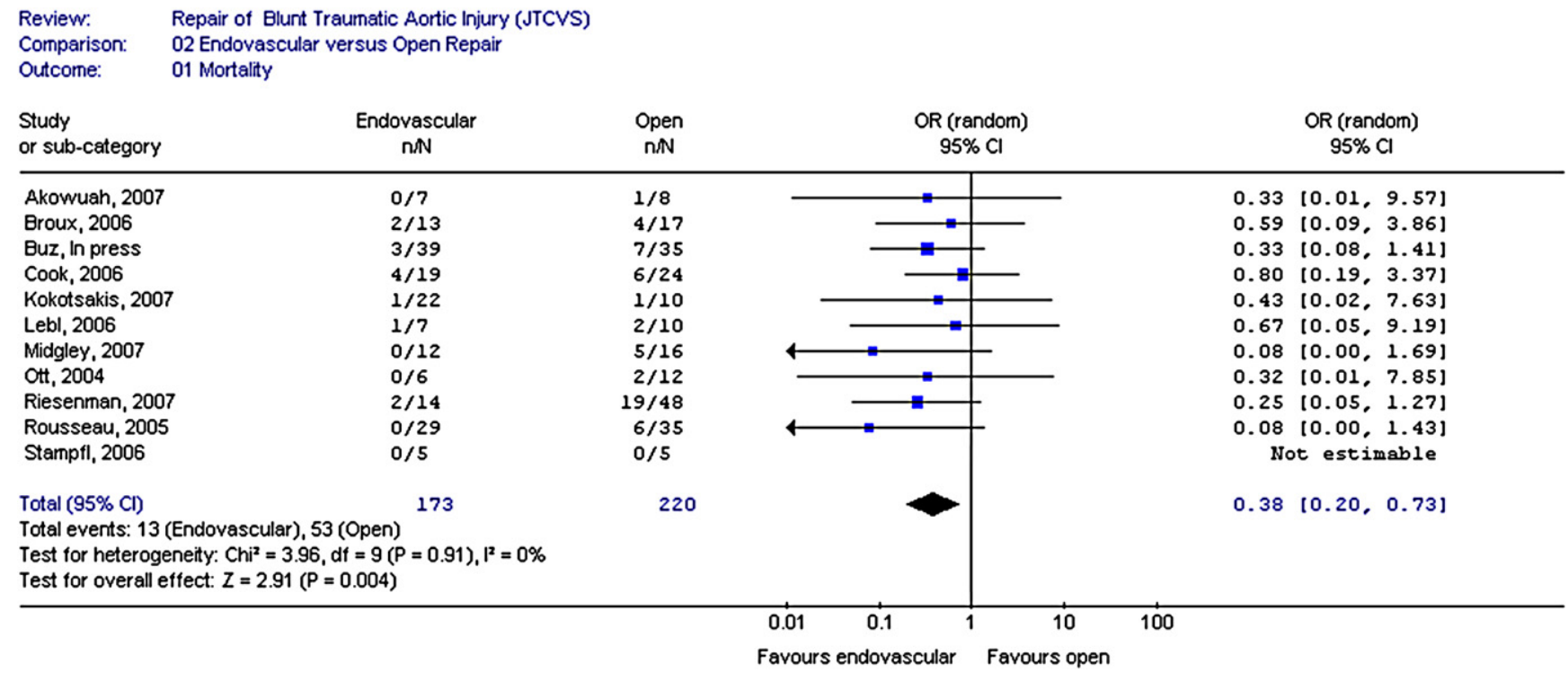

Figure 1. Meta-analysis of mortality of endovascular versus open repair. The upper and lower panels included all 17 studies and the 11 studies with similar preoperative variables in both groups, respectively.

better evidence, because it is difficult to recommend prospective randomized controlled trials that have never been conducted.

\section{References}

1. Buz S, Zipfel B, Mulahasanovic S, Pasic M, Weng Y, Hetzer R. Conventional surgical repair and endovascular treatment of acute traumatic aortic rupture. Eur J Cardiothorac Surg. In press (doi:10.1016/j.ejcts.2007.10.017).

2. Kokotsakis J, Kaskarelis I, Misthos P, Athanasiou T, Kanakakis K, Athanasiou $\mathrm{C}$, et al. Endovascular versus open repair for blunt thoracic aortic injury: short-term results. Ann Thorac Surg. 2007;84:1965-70.
3. Riesenman PJ, Farber MA, Rich PB, Sheridan BC, Mendes RR, Marston WA, et al. Outcomes of surgical and endovascular treatment of acute traumatic thoracic aortic injury. J Vasc Surg. 2007;46: 934-40.

4. Akowuah E, Baumbach A, Wilde P, Angelini G, Bryan A. Emergency repair of traumatic aortic rupture: endovascular versus conventional open repair. J Thorac Cardiovasc Surg. 2007;134:897-901.

5. Midgley PI, Mackenzie KS, Corriveau MM, Obrand DI, Abraham CZ, Fata P, et al. Blunt thoracic aortic injury: a single institution comparison of open and endovascular management. J Vasc Surg. 2007;46: $662-8$. 


\section{E-References}

E1. Amabile P, Collart F, Gariboldi V, Rollet G, Bartoli JM, Piquet P. Surgical versus endovascular treatment of traumatic thoracic aortic rupture. J Vasc Surg. 2004;40:873-9.

E2. Andrassy J, Weidenhagen R, Meimarakis G, Lauterjung L, Jauch KW, Kopp R. Stent versus open surgery for acute and chronic traumatic injury of the thoracic aorta: a single-center experience. J Trauma. 2006;60:765-72.

E3. Broux C, Thony F, Chavanon O, Bach V, Hacini R, Sengel C, et al. Emergency endovascular stent graft repair for acute blunt thoracic aortic injury: a retrospective case control study. Intensive Care Med. 2006;32:770-4.

E4. Cook J, Salerno C, Krishnadasan B, Nicholls S, Meissner M, Karmy-Jones R. The effect of changing presentation and management on the outcome of blunt rupture of the thoracic aorta. J Thorac Cardiovasc Surg. 2006;131:594-600.

E5. Doss M, Balzer J, Martens S, Wood JP, Wimmer-Greinecker G, Fieguth HG, et al. Surgical versus endovascular treatment of acute thoracic aortic rupture: a single-center experience. Ann Thorac Surg. 2003;76:1465-70.

E6. Kasirajan K, Heffernan D, Langsfeld M. Acute thoracic aortic trauma: a comparison of endoluminal stent grafts with open repair and nonoperative management. Ann Vasc Surg. 2003;17:589-95.

E7. Lebl DR, Dicker RA, Spain DA, Brundage SI. Dramatic shift in the primary management of traumatic thoracic aortic rupture. Arch Surg. 2006;141:177-80.

E8. Ott MC, Stewart TC, Lawlor DK, Gray DK, Forbes TL. Management of blunt thoracic aortic injuries: endovascular stents versus open repair. J Trauma. 2004;56:565-70.

E9. Pacini D, Angeli E, Fattori R, Lovato L, Rocchi G, Di Marco L, et al. Traumatic rupture of the thoracic aorta: ten years of delayed management. $J$ Thorac Cardiovasc Surg. 2005;129:880-4.

E10. Reed AB, Thompson JK, Crafton CJ, Delvecchio C, Giglia JS. Timing of endovascular repair of blunt traumatic thoracic aortic transections. J Vasc Surg. 2006;43:684-8.

E11. Rousseau H, Dambrin C, Marcheix B, Richeux L, Mazerolles M, Cron C, et al. Acute traumatic aortic rupture: a comparison of surgical and stent-graft repair. J Thorac Cardiovasc Surg. 2005;129:1050-5.

E12. Stampfl P, Greitbauer M, Zimpfer D, Fleck T, Schoder M, Lammer J, et al. Mid-term results of conservative, conventional and endovascular treatment for acute traumatic aortic lesions. Eur J Vasc Endovasc Surg. 2006;31:475-80. 